\title{
Enhancing CRM Business Intelligence Applications by Web User Experience Model
}

\author{
Natheer K. Gharaibeh \\ College Computer Science and Engineering at Yanbu, Taibah University \\ Yanbu, KSA
}

\begin{abstract}
CRM technology which promises a brighter future of more profitable customers and decreasing costs. One of the most critical trends is enhancing Business Intelligence applications using Web Technologies, Web technologies can improve the CRM BI implementation, but it still need evaluation, The Web has focused the attention of organizations towards the User Experience and the need to learn about their customer, The UX paradigm calls for enhancing CRMBI by Web technologies. This paper deals with this issue and provide a framework for building Web based CRMBI depending on the Process mapping between CRMBI and UX. It provides a conceptual overview of CRM and its relationship to the main disciplines $\mathrm{BI}, \mathrm{UX}$ and Web.
\end{abstract}

Keywords-CRM; Data warehouse; User Experience; Business intelligence; Web

\section{INTRODUCTION}

Business Intelligence and Web Technologies [1] [10] has gained greater attention since the last two decades. for both practitioners and researchers BI includes business-centric practices and methodologies that can be applied to various high-impact applications such as e-commerce, market intelligence, customer intelligence and specifically customer relationship management (CRM). The high failure rates reported [2] in CRM Applications raised questions about how CRM applications are developed and especially what Design preconditions are required for implementing and building CRM successfully.

Analysts such as Gartner, AMR and Forrester Research studied the problem seriously From 2001 till 2009, a variety of analyst firms reported failure rates ranging up to 70 percent, with over 50 percent of organizations in 2009 indicating that CRM projects did not fully meet expectations, and it was noted 1 that the percentage of firms implementing CRM has increased, from 53 percent in 2003 to 75 percent in 2010.

As with the problem of CRM, it is founded that $50 \%$ to $66 \%$ of all initial Business Intelligence and DW efforts fail [3]. Gartner [4] estimates that more than $50 \%$ of DW projects have limited acceptance or fail. Therefore, it is crucial to have a thorough understanding of the critical success factors and variables that determine the efficient implementation of a DW solution. What is interesting to note that two of the top three CSFs were focused on understanding the business context and process in which the data warehouse would operate. From this

${ }^{1}$ http://www.destinationcrm.com/Articles/Editorial/Magazine-Features/CRMThen-and-Now-68083.aspx perspective we want take CRM as the business context and the process that need to be improved.

To illustrate a good starting point between CRM and BI, on the one hand, there is a general acceptance among researchers [5] of the categorization of CRM components into Technology, people, and Process. On the other hand, Gartner [4] provides these three pillars as working framework for the success of BI , the intermediate pillar is process which represents the connection between people and technology [6] , therefore ,There is essential shift toward process orientation of BI [7] , By applying Process oriented BI We Replace function-oriented separation of work by processes that span both functional and organizational boundaries, Therefore CRM as a process has been added to BI To coin the concept of CRMBI applications.

Thus, we define CRMBI as all BI capabilities that are dedicated to the analysis as well as to the systematic purposeful transformation of CRM relevant data from communication , transactional level into relational level, this implies the transformation from reach to richness [1], Reach means make communication with large numbers of customers, while Richness means more meaningful communication with those customers through real transactions, and then establish useful relations with those loyal customers. This relational model must be done through Web based applications in order to access larger number of people. This is what we mean by Web Based CRMBI Application. CRMBI can be exist in many forms and examples, in this study the problem at hand is Frequent Flyer Program (FFP) from the Airline application domain, which will be explained in section 5 .

There are a lot of research about how to combine between CRM and BI, but there is a little research about extending the capabilities of CRM Business Intelligence applications by web , the importance of web come from meeting the requirements of large numbers of connected customers and the huge amount of available c lick stream data available through the web. Furthermore, the processes of connecting with customers through the Web are a key resource that will enable the organization strengthen its relationships with their customers and gain a sustainable competitive advantage., The Web has focused the attention of organizations towards the User Experience [8] and the need to learn about their customer, The UX paradigm calls for enhancing CRMBI by web technologies. In this paper the Process mapping between CRMBI and UX will be discussed.

In order to get insight into the development process of CRMBI, a design science approach was applied in this paper, 
the following structure was organized. In the second section some background information on the main concepts of the paper will be provided. A more detailed overview of the main concepts (CRM, BI, UX and Web) are presented in section 3. Subsequently, a vision for the CRMBI process is outlined in Section 4. whereas section 5 offer a detailed analysis of the main components of the developed model. In section 6 conclusions are drawn.

\section{BACKGROUND}

In this section, every concept and its relationship with the problem at hand are explained.

\section{A. CRM and relational function}

There are many determinants for the CRM, but in this paper the determinants of e-relationship quality in most recent CRM literature [22] [23] will be followed: the communicational function, followed by transactional function and then relational function, these three dimensions were the most important dimensions that would affect customer loyalty as indicator for CRM Success.

Communication function represents the use of Internet as customer service tool to display information and answer all enquiries from customers. Transactional function represents the use of Internet technology as a platform to transact with companies such as place orders, accomplishing payments, and view profile of previous activities. Relational function consists of value adding elements such as customized services and personalized Web Pages. In this paper the focus will be transferred from Communication to transactional, then from transactional to the relational level. The containment of these three levels will five a broader vision of building CRMBI, which is the main goal of this paper.

\section{B. DW as a specific Research Area (The need to expand capabilities of $D W$ )}

Since 30 years data warehouses [25] have been deployed as an integral part of a modern decision support environment. Therefore, a DW/BI is not only a software package or product, it also a process. The adoption of DW technology requires massive capital expenditure and a certain deal of implementation time. DW projects are hence very expensive, time-consuming and risky undertakings compared with other information technology initiatives, as cited by prior researchers [7]. Further Project Management practices do not work easily on DW [14], because they needs more integration with other systems, developing DW is a process more than product. Moreover, the DW/BI projects can't be initiated unless their benefits have been associated to the organization's specific business problems and strategic business goals [14]. Justification for a DW initiative must always be businessdriven and not technology-driven. So it is very important for such projects to get support from top level management.

Although a data warehouse empowers knowledge workers with information that allows them to make decisions based on a solid basis of fact. However, only a fraction of the required knowledge exists on computers; the vast majority of a firm's intellectual assets exist as knowledge in the minds of its employees, in the form of tacit knowledge [24]. Hence, a data warehouse does not necessarily provide adequate support for knowledge intensive queries in an organization. This situation can be interpreted as a sign that the field of BI development must enter into new stage of multi-perspectives research, which depends more on Web technologies. This viewpoint copes with the DW research agenda proposed by Nemati et al. [25]. They said, bone research area of decision support technologies such as BI and DW needs to the development of a set of theoretical foundations upon which to build future applications.

Since the early 2000s, the Internet and the Web began to offer unique data collection and analytical research and development opportunities which extend and enhance the CRM and BI applications. Especially IP-specific user search and interaction logs [10], Before that there where many difficulties in collecting this huge amount of customer data [28], but now with the advance in Web2.0, Web intelligence, web analytics, and the user-generated content have led to a new and exciting era of BI\&A 2.0 research [10] which is centered on text and web analytics for unstructured web contents. In which the customer data can be collected seamlessly through cookies and server logs have become a new gold mine for understanding customer's needs and identifying new business opportunities.

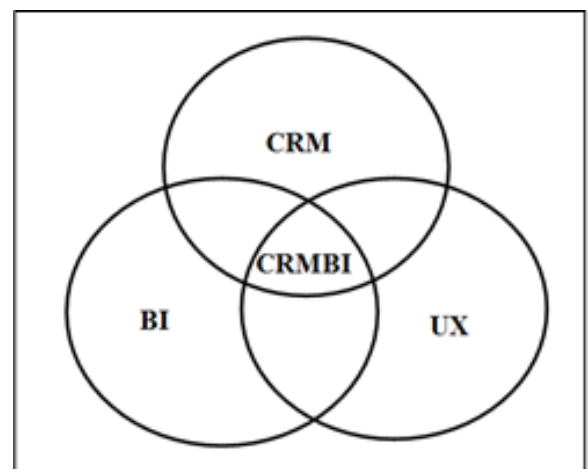

Fig. 1. Intersection between three Areas

What is needed is a new generation of DW that provides the infrastructure required to capture not only data and information but also knowledge. The existing data warehouses model can be extended and enhanced by Web Technologies to create a knowledge as we will show in the next section. The key idea of Web 2.0 [26] is putting the user at the center. It enables people to participate, collaborate and interact with each other. Web 2.0 has become a mass phenomenon.

\section{C. $C R M B I$}

As we defined CRMBI in the introduction, in this section we will show more details about this concept. At a general level, development of Web based CRMBI applications depend on the combination of the three main areas, CRM, BI, and UX as depicted in Figure 1. CRMBI can be found at the intersection of these three circles. The research problems originate from both CRM and BI fields in a way that Web technologies provide solution for both problems. By doing this we increase the opportunity of developing CRMBI successfully. By taking the impacts of these important fields on the required Software Artifact. In the next sections a new framework for CRMBI development will be presented. This 
review of theory and practice of CRM, BI and Web will help the Information System developers and Business analysts to have a clear mind of the development of CRMBI applications. This kind of studies is exploratory in nature, and it may be the seed for ongoing research on more than one emergent direction. To provide concrete evidence of applicability a technical vision for the possible CRMBI implementation is introduced in section 5 .

\section{CRMBI AND UX}

\section{A. The three CRM Processes}

Through transferring from just Communication with customers into Transactional function. a Data base or ARS (Airline Reservations System) is created and updated, The value-adding features such as personalized recommendations personalized webpages, and customized service could be established in the relational function

These three functions of CRM could be mapped into the five elements of user experience, which will be shown in the next section.

\section{B. User experience elements}

Most people, at one time or another, have reserved a ticket (or any other service) over the Web. The experience is pretty much the same every time, the customer go to the site, he find the flight he want, maybe by using a search engine, by browsing a catalog or maybe by a Third-party online intermediaries (TPIs), then after this Communication, the customer give the site his credit card number and his address, and the site confirms that the book will be shipped to him.

These orderly experience actually emerges from a whole set of decisions about how the Web Site looks, how it behaves, and what it allows you to do. These decisions build upon each other, informing and influencing all aspects of the user experience. Garret [8] introduces five elements of user experience by concepts underlying software or a website. These application concepts summarize the goals a software system should pursue. Garrets elements collectively introduce different levels of such application concepts represented in an information system, which is described in Figure 2.

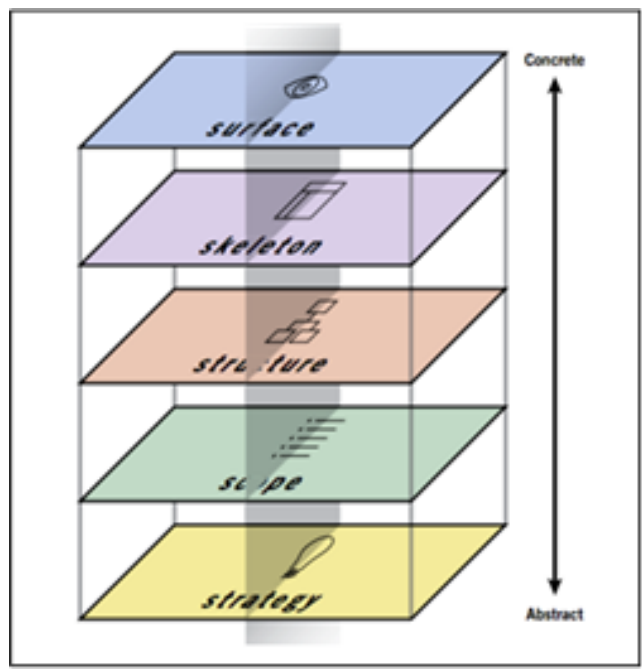

Fig. 2. elements of User experience
According to Reichheld and Schefter [9] an increase in customer retention rates by only $5 \%$ can increase profits by $25 \%$ to $95 \%$. Consequently, the development of loyal customer behavior is a valued goal for CRMBI developers and designers. Creation of a sustaining User experience that encourages customers to return to the site and purchase requires Web site properties that achieve the customer's expectations. Garrett [8] asserts that the user experience is an instrument for building customer loyalty

\section{The Importance of Web for CRMBI Success}

Recent literature has placed the Web Technologies such as the more significant Critical Success Factor in the implementation of a CRM and BI [10], the importance of integrating Web [11] into data warehousing environments Come through enabling knowledge workers to acquire, integrate and flexibly analyze information from different sources aiming to improve the knowledge assets of the enterprise. These operation need larger architecture to be applied, therefore the operational data store (ODS) [12] has been introduced as a way of interfacing of the Web environment to the data warehouse.

Since the processes of customers are a key resource that will enable the company strengthen its relationships with them and gain a sustainable competitive advantage., The Web has focused the attention of organizations towards the User Experience [8] and the need to learn about their customer, The UX paradigm calls for extending the capabilities of CRMBI through Web technologies, This represents the main driving factor towards Web based CRMBI and give more importance to the users by using personalization methods [13] , in which an overall customized user experience is provided by taking into account the needs, preferences and characteristics of a user or group of users, this personalization consists of defining and exploiting a user profiles. In addition to ODS we need Granularity Manager [12], which is positioned between the Web site and the data warehouse. The purpose of the granularity manager is to edit, aggregate, summarize, and integrate data as it passes from the Web to the data warehouse.

By referring to UX Garrett's model and Levels of Process in CRM which was expressed in 3.1 , we argue that representation and direct mapping between these two different concepts could enhance CRMBI. Table 1 shows this.

TABLE I. PROCESS MAPPING BETWEEN CRMBI AND UX

\begin{tabular}{|l|l|l|}
\hline CRM level & UX element & CRMBI component \\
\hline $\begin{array}{l}\text { Relational } \\
\text { level }\end{array}$ & Strategy & $\begin{array}{l}\text { GM and ODS in FFP } \\
\text { (OLAP) }\end{array}$ \\
\hline $\begin{array}{l}\text { Transaction } \\
\text { level }\end{array}$ & Scope & $\begin{array}{l}\text { The daily reservation } \\
\text { Database in ARS } \\
\text { (OLTP) }\end{array}$ \\
\hline $\begin{array}{l}\text { Communicati } \\
\text { on level }\end{array}$ & $\begin{array}{l}\text { structure, } \\
\text { skeleton, and } \\
\text { surface }\end{array}$ & $\begin{array}{l}\text { Web Site User } \\
\text { Interface }\end{array}$ \\
\hline
\end{tabular}




\section{CRMBi STRATEGY PLAN}

As it has been shown in the introduction, building CRMBI is not operational nor tactical, instead of that it must begin at the strategic level, because DW is not only system that is built or product you can buy [14], but also it is process of building a OLAP (Online Analytical Processing) system that must be integrated into other OLTP (Online Transaction Processing) systems. In this section the process will be improved at the strategic level, and a vision for the possible CRMBI technical implementation is introduced by exploiting the Web Technologies.

This first require Understanding CRM Process at the relational level, with its mapping element In UX, the Strategy, this phase include [8] Success metrics, user needs and Customer Segmentation

\section{A. Loyalty as indicator for CRMBI Success}

Because we are dealing with a Problem of empirical basis, we can follow the Critical thinking [15] approach by taking the position that certain elements within a problem context are more critical to the solution, It is therefore [16] crucial for a company to direct its marketing efforts towards retaining the top $20 \%$ of existing customers rather than spending it on communicating with customers who are likely to be unprofitable.

The key for successful development of CRM application [27] is to focus on measuring and managing customers with the intention to create loyal and profitable customers is to build lasting relationships with customers through identifying, understanding and meeting their needs. Identifying the most profitable customers has been a difficult task, but mixing of Data Warehousing and web technology has enabled companies to start pursuing this goal with a whole new level of intensity.

While relationships are a central part of loyalty, they alone are not enough to build CRMBI application; this what this research is trying to answer. The process of building customer loyalty is often described using a loyalty ladder [18] with five ascending steps: suspect, prospect, customer, client and advocate. This issue will be discussed in the next subsection.

\section{B. User Segmentation}

Historical data could be provided by Data warehouses [12], in which a time variant approach is used, where transactional data is summarized and kept to future uses, this need approaches of how data evolve from transactional focus to a relational customer focus. There is little theoretical empirical research that meaningfully addresses issues of how companies evolve from a transactional focus to a relational customer focus. Furthermore, while customer segmentation (or customer classification) [19] can be a powerful analysis, there are some limitations on using single classification techniques when the customer may belong to multiple segments (or classifications). Cunningham [19] discussed data mining algorithms can be classified into three categories:
1) math-based methods such as neural networks and linear discriminant analysis,

2) distance-based methods and

3) logic-based methods such as decision trees and rule induction.

Although these methods are powerful and accurate but they can be time consuming, especially for business analysts and Software developers. So, another potential research area would be to develop better software development methodologies that can be used efficiently and effectively to analyze customers that belong to multiple segments. This goal can be achieved by expanding the CRMBI Application by Web Technologies.

\section{Voice Of the Customer}

In the following scenario The researcher played the role of A passenger: he reserved through One of the travel agents who use Sabre distribution system, it seems that the agent didn't match the FFP correctly, or there is a problem in integration between Sabre and Amadeus (which mostly used by RJ)

When the passenger returns to his FFP account he didn't find his recent flights, after the passenger tried to submit the claim to RJ, he was asked to enter the Ticket Number and rest of Flight information.

But This FFP assigning process needs from the passenger long time to collect all the data, further he couldn't do that, because he has no access to the Data Base, especially if his family members were registered with the family account, further to the fact that he traveled several number of times, therefore the FFP assigning process must be automatic, in order to avoid this problem [20], the CRM Process must be reengineered, this could be done through 6 Sigma Improve step , the following case study will show that.

This mean that personalizing a system consists of defining and exploiting a user profile which is in our case the FFP for the passenger or customer, the FFP refine and aggregate data taken from the ARS Data Base, which is considered transactional systems, this must be done automatically but unfortunately this is done manually in many Airlines companies, Royal Jordanian one of these companies,

\section{THE SOLUTION ARCHITECTURE}

In Traditional Operational systems (OLTP), Transactions and reservations [21] are fine grained and are agent to change; by contrast, data warehouse (OLAP) information is much more coarse grained and is refreshed according to a careful choice of refresh policy,

To guarantee efficiency for the fine-grained Transaction system and effectiveness for the coarse grained data warehouse, we need an important component in CRMBI, Which is the ODS mentioned in figure 3. The ODS is a hybrid structure that has some aspects of a data warehouse and other aspects of an operational system, 


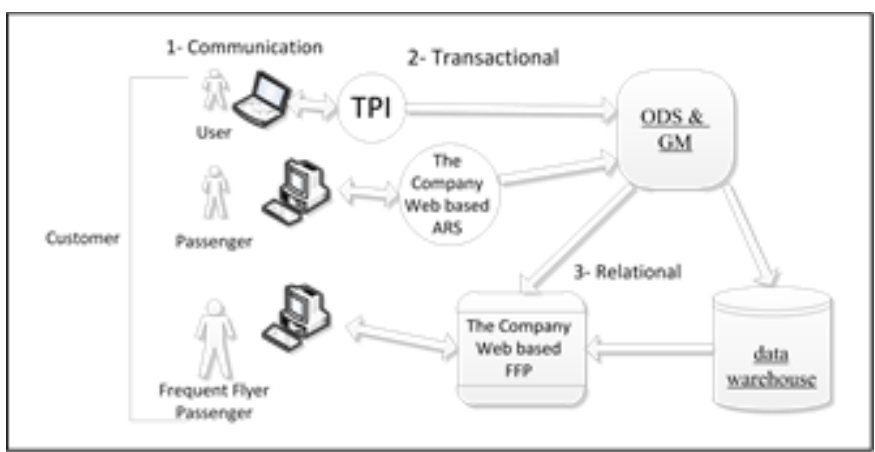

Fig. 3. CRMBI Process Steps

We have to increase the ability to collect fine-grained, location-specific, context-aware, highly personalized content [10] through many sources, for example: Third-party online intermediaries (TPIs) such as Kayak, destina , Expedia Travelocity, or Orbitz, this Click stream data is almost always at too high level of fine-grained granularity. It is the job of the granularity manager to condense the click stream data into the proper level of granularity (more coarse grained) before it passes into the data warehouse and FFP.

\section{A. The three CRMBI levels of process}

The following steps shows the gradual refinement of the customer from prospected users into advocate passengers and finally members in FFP.

\section{1) Communication level UI}

This level begin communicating with customers (which may be passengers or users) at the first moments, by knowing their IP addresses or even by catching their data through forms , As Web users interact with websites via these User Interfaces they are providing a enormous foundation of Clickstream data about their behavior. This raw data can possibly reveal extraordinary details about the customers' usage and wishes, through which ARSs and TPIs will refine their reports and summaries; there are many examples show scenarios of booking flights through the internet which will be considered ARS, besides the Company own log files, it can also get clickstream data from different parties. it may get clickstream data from referring partners, you can reserve a ticket from any TPI, e.g.: Kayak, destina , Expedia or others

\section{2) Transaction level}

The customers enters their data through reservation form (flight's number, segment, Source and destination etc.), this data is stored into reservation table, as this transaction happens many times for many passengers per specific period of time, this information is recorded in ODS, which in turns is responsible for analyzing the flight activities of each member to be sent to FFP, which in turns interested in seeing what flights the company's frequent flyers take.

\section{3) Relational level}

In updating FFP the number of passengers who fly frequently is determined, If the same passenger travels more than o nce, then he is candidate to be a member in FFP, FFP system should depends on the type of customer, or the membership tier, which is divided into many segmentation levels: Blue Plus, Silver Plus, Gold Plus and Platinum Plus.
This Tiers structure makes it easier for the passengers or members to qualify to the higher tiers based on either the miles they accumulate or the number of segments they travel. It also makes it easier for them to maintain their tier for another year.

\section{CONCLUSION}

The study aims to exploits CRM determinants (Communication, Transaction and Relational functions) to gain loyal customers through CRMBI process. Which leads to the development of Web based CRMBI applications depending on the combination of the three main areas, CRM, BI, and UX

The scope of this work fall in the topic of integration of operational CRM (OLTP) and the analytical CRM (OLAP), this idea expressed in the solution architecture, which shows the life cycle of shifting customers from users at the communication level, passengers who reserve a ticket at the transaction level, and finally Frequent Flyer Passenger at the relational level.

\section{REFERENCES}

[1] Ramesh Sharda, Dursun Delen, Efraim Turban and David King, Business Intelligence: A Managerial Perspective on Analytics (3rd Edition), 2013.

[2] Joseph Przybyla and Ann Parker ,'Customer Relationship Management Systems: Why They Fail, How to Succeed" , 2013, http://www.elite.com/exchange/2013/spring/pdf/BD_CRM_WhyTheyFa il_wp_L-384265US_4-13.pdf_, accessed in 15/6/2015

[3] Kimpel, J.F and Morris, R. . "Critical success factors for data warehousing: a classic answer to a modern question", Issues in Information Systems, 2013 , Volume 14, Issue 1, pp.376-384.

[4] IBM: A practical framework for business intelligence and planning in midsize companies - featuring research from Gartner. http://www304.ibm.com/businesscenter/cpe/download0/211180/practicalframework .pdf (accessed May 1. 2015)

[5] Chen, I. J. and Popovich, K., "Understanding Customer Relationship Management - People, Process and Technology"; Business Process Management Journal, 9, 5, (2003), 672-688.

[6] Edwards, J. S. (2009). Business processes and knowledge management. In M. Khosrow-Pour (Ed.), Encyclopedia of Information Science and Technology (Second ed., Vol. I, pp. 471-476). Hershey, PA: IGI Global.

[7] Tobias Bucher and Anke Gericke, 2009, "Process-centric business Intelligence", Business Process Management Journal, Vol. 15 No. 3, 2009, pp. 408-429, DOI 10.1108/14637150910960648

[8] Garrett, J. J. (2006). Customer loyalty and the elements of user experience. Design Management Review, 17(1), 35-39.

[9] Cyr, D. Bonanni, C, and Ilsever, J. "Design and E-loyalty Across Cultures in Electronic Commerce". Sixth International Conference on Electronic Commerce (ICEC04), Delft, Netherlands, 2004.

[10] Hsinchun Chen, Roger H. L. Chiang, Veda C. Storey, "Business Intelligence and Analytics: From Big Data to Big Impact". MIS Quarterly 36(4): 1165-1188, 2012.

[11] Matteo Golfarelli, Stefano Rizzi, "Data warehouse design from XML sources", DOLAP 2001: 40-47

[12] Inmon , Building the Data Warehouse, 4th Edition , John Wiley and Sons, ISBN 978-8-1265-0645-3, 2005 .

[13] Eya Ben Ahmed, Ahlem Nabli, Faïez Gargouri , “A Survey of UserCentric Data Warehouses: From Personalization to Recommendation". International Journal of Database Management Systems ,2011.

[14] Larissa T. Moss, Extreme Scoping: An Agile Approach to Enterprise Data Warehousing and Business Intelligence, Perfect PaperbackAugust 15, 2013

[15] Marakas, G. M. (2003).Decision support systems in the 21st century. Upper Saddle River, NJ,Prentice Hall. 
[16] Sathyapriya.P, Naghabushana R, and Silky,(2012)."Customer Satisfaction of Retail Services Offered in. Palamudhir Nizhayam" International Journal of Research in in Finance \& Marketing .

[17] Abu-Kasim, N.A. and Minai, B. (2009). Linking CRM strategy, Customer performance measures, and performance in Hotel Industry. International Journal of Economics and Management, 3(2), 297-316.

[18] Roberts, Mary Lou \& Berger, Paul D. (1999). Direct Marketing Management. Second Edition. Upper Saddle River: Prentice-Hall, Inc.

[19] C. Cunningham, I. Song, and P.P. Chen, "Data Warehouse Design to Support Customer Relationship Management ", ;presented at Database Technologies: Concepts, Methodologies, Tools, and Applications, 2009, pp.702-724.

[20] Tullis, Tom; Albert, Bill (2008). Measuring the User Experience: Collecting, Analyzing, and Presenting Usability Metrics. Morgan Kaufmann.

[21] Ramez Elmasri, Shamkant B. Navathe, Fundamentals of Database Systems (6th Edition), April 9, 2010

[22] Asgari (2012) The Association between Three Dimensions of eRelation ship Quality in Lodging. Advanced in Modern Management Journal, VOL.1, NO.1.
[23] Ab Hamid, N. R . E-CRM: Are we there yet? Journal of American Academy of Business, Cambridge, 6(1), 2005,pp 51-57.

[24] Nonaka, "A Dynamic Theory of Organizational Knowledge Creation", Organization Science, Vol. 5, No. 1, 1994, pp.14-37.

[25] Nemati, H., Steiger, D. , Iyer ,L., Herschel, R, "Knowledge warehouse: an architectural integration of knowledge management decision support, artificial intelligence and data warehousing", Journal of Decision Support Systems 33, , 2002,43- 161.

[26] Bebensee,T., Helms,R., \& Spruit,M. (2012). Exploring the Impact of Web 2.0 on Knowledge Management. In Boughzala,I., \& Dudezert,A. (Eds.),Knowledge Management 2.0: Organizational Models and Enterprise Strategies (pp. 17-43). IGI Global.

[27] Abu-Kasim, N.A. and Minai, B. , Linking CRM strategy, Customer performance measures, and performance in Hotel Industry. International Journal of Economics and Management, 3(2), 2009, pp 297-316.

[28] Kimball, Ralph \& Ross, Margy (2002). The Data Warehouse Toolkit: The Complete Guide to Dimensional Modeling, Second Edition: John Wiley \& Sons 